\title{
Evidências e fatores associados ao fenômeno de adiamento da maternidade no Brasil
}

\author{
Marina Silva da Cunha* \\ Ana Maria Paula Rosa** \\ Marcos Roberto Vasconcelos ${ }^{\star \star *}$
}

Este trabalho tem como objetivo contribuir com a literatura sobre o fenômeno do adiamento da maternidade no Brasil, bem como analisar seus principais fatores associados. A pesquisa aborda o período de 1992 a 2015, considerando as informações da Pesquisa Nacional por Amostra de Domicílios (PNAD), do IBGE, e a análise de sobrevivência que possibilita caracterizar aquelas mulheres com nascimentos de primeira ordem. Os resultados constatam uma tendência crescente da postergação da maternidade no Brasil e que aquelas com mais chances de adiar a maternidade são brancas, solteiras, residentes em áreas urbanas, metropolitanas e na região Sudeste. Ademais, foi possível identificar que, entre os principais fatores que contribuem para essa tendência, estão o investimento em capital humano e a participação no mercado de trabalho, preponderantes para o adiamento da maternidade.

Palavras-chave: Adiamento da maternidade. Primeiro filho. Mercado de trabalho.

\footnotetext{
* Universidade Estadual de Maringá (UEM), Maringá-PR, Brasil (mscunha@uem.br; https://orcid.org/0000-0001-9122-3944). ** Universidade Federal do Rio Grande do Sul (UFRGS), Porto Alegre-RS, Brasil (anamarypr@hotmail.com; https://orcid. org/0000-0003-0182-2164).

*** Universidade Estadual de Maringá (UEM), Maringá-PR, Brasil (mrvasconcelos@uem.br; https://orcid.org/0000-00031476-4899).
} 


\section{Introdução}

A partir de meados do século XX, especialmente após a década de 1960, com o barateamento e a popularização dos artifícios contraceptivos e a ampliação de políticas públicas direcionadas ao controle da natalidade e planejamento familiar, a queda das taxas de fecundidade se disseminou pelo mundo, inclusive nos países em desenvolvimento (KNODE; CHAMRATRITHIRONG; DEBAVALYA, 1987; GOLDIN; KATZ, 2002). Conforme dados do Banco Mundial, em 1961, o mundo apresentava uma taxa de fecundidade total média de 5,0 filhos por mulher, que diminuiu para 3,7 em 1980, terminou o milênio em 2,7 e chegou a 2,5 em 2015. De forma ainda mais acentuada, o Brasil acompanhou esse movimento declinante e encerrou o século XX com uma taxa de fecundidade total de 2,3 filhos por mulher, atingindo 1,7 em 2017, patamar similar a países com alto grau de desenvolvimento socioeconômico, tais como Austrália, Inglaterra, Holanda e Noruega (THE WORLD BANK, 2018).

De fato, em meados da década de 2000, o comportamento de queda das taxas de mortalidade e fecundidade inseriu o Brasil na fase de transição demográfica caracterizada por taxas de fecundidade abaixo do nível de reprodução de sua população. Segundo a Pesquisa Nacional por Amostra de Domicílios (PNAD), realizada pelo IBGE, esse nível foi atingido em 2004, quando a taxa de fecundidade era de 2,1. Destaca-se que o ritmo dessas mudanças demográficas tem sido mais acelerado nos países em desenvolvimento, como o Brasil, do que naqueles mais desenvolvidos (BRITO, 2008; MIRANDA-RIBEIRO; GARCIA, 2013). Adicionalmente, níveis baixos de fecundidade e mudanças na estrutura das famílias podem caracterizar a segunda transição demográfica (ZALDI; MORGAN, 2017; MIRANDA-RIBEIRO; GARCIA, 2013).

Entre os fatores que têm contribuído para a redução da taxa de fecundidade está o adiamento da maternidade. Postergar a maternidade pode levar a dificuldades na concepção devido ao declínio da fertilidade com a idade, pois, mesmo com a utilização das técnicas de reprodução assistida, as mulheres podem não recuperar os nascimentos adiados (LERIDON, 2004). A ascensão na carreira profissional e a falta de um parceiro adequado com quem deseja ter filhos se refletem em uma relação negativa entre a idade na entrada na maternidade e o tamanho da família concluída (ALDRIGHI et al., 2016). E o adiamento da maternidade ainda é um fenômeno em ascensão, identificado pelo fato de que, em igualdade de circunstâncias, coortes mais recentes têm seu primeiro filho cada vez mais tarde na vida. Porém, se aquelas que diferem a maternidade tendem a obter maior sucesso na carreira profissional, elas têm menos anos de fertilidade e podem enfrentar um aumento dos riscos de saúde para si e seus filhos, caso decidam tê-los (MILLER, 2009).

Assim, a decisão de procrastinar a maternidade tem repercussões importantes tanto sobre a dinâmica demográfica, pelo denominado efeito-tempo sobre a taxa de fecundidade total (BONGAARTS; FEENEY, 1998), quanto sobre a inserção e a desigualdade salarial e ocupacional feminina no mercado de trabalho. A discussão a respeito do adiamento da maternidade vem recebendo crescente atenção na literatura internacional (SOBOTKA, 2004; 
BILLARI; LIEFBROER; PHILIPOV, 2006; MILLS et al., 2011). Estudos têm verificado diferenças raciais no adiamento da maternidade, influência de fatores culturais, políticos e econômicos (MILLER, 2009), incerteza econômica e renda familiar (O'DONOGHUE; MEREDITH; O'SHEA, 2009) e interferência do ciclo econômico (ADSERA; MENENDEZ, 2009).

$O$ fenômeno do adiamento da maternidade tem sido observado nos países desenvolvidos desde a década de 1980 (SOBOTKA, 2004, BILLARI; LIEFBROER; PHILIPOV, 2006). No Brasil, Miranda-Ribeiro (2007) e Miranda-Ribeiro, Rios-Neto e Ortega (2008) observaram que, até o início dos anos 1990, ocorreu no país um efeito tempo negativo, ou seja, a antecipação dos nascimentos dos filhos refletida na queda da idade média de fecundidade, o que aumentava a taxa de fecundidade total no país. No início da década de 2000 , Miranda-Ribeiro, Rios-Neto e Ortega (2008) não verificaram mais mudanças na idade média de fecundidade de primeira ordem, mas encontraram evidências de adiamento do segundo filho já a partir de meados da década de 1990. Para Miranda-Ribeiro (2007), ao final dos anos 1990, o Brasil apresentava evidências de ingresso em uma fase na qual o movimento de queda da taxa de fecundidade seria fomentado pela postergação da maternidade. Miranda-Ribeiro, Garcia e Faria (2019) reforçaram as evidências de redução da fecundidade e do adiamento da maternidade no país entre as décadas de 1990 e 2000.

Buscando contribuir com essa literatura para o Brasil, o presente trabalho tem como objetivo analisar o adiamento da maternidade ou dos nascimentos de primeira ordem, evidenciando esse fenômeno do começo dos anos 1990 até 2015, além de identificar os seus principais fatores associados. Para tanto, foram utilizadas a metodologia de análise de sobrevivência e as informações da PNAD desde 1992, quando essa pesquisa incorporou perguntas sobre a fecundidade de forma regular, permitindo seu acompanhamento até $2015 .^{1}$

Na seção a seguir é realizada a revisão da literatura sobre os fatores associados ao adiamento da maternidade. Posteriormente expõe-se a abordagem metodológica, com a fonte de informações e o método empregado. É feita uma análise descritiva dos dados no período e são discutidos os resultados do trabalho. Por fim, apresentam-se as considerações finais.

\section{Adiamento da maternidade}

A entrada na maternidade em idade cada vez mais elevada tem sido associada à redução da fecundidade nos países europeus, conforme indicaram Gustafsson (2001), Sobotka (2004) e Billari, Liefbroer e Philipov (2006), pois isso implicou a redução do período reprodutivo disponível e, portanto, da capacidade de geração de filhos. Vários fatores estariam impulsionando a tendência de postergação de maternidade, como as mudanças ideacionais

\footnotetext{
${ }^{1}$ Infelizmente, tais informações deixaram de ser levantadas na Pesquisa Nacional por Amostra de Domicílios Contínua, implementada a partir de 2012 e substitutiva da pesquisa anterior, não permitindo um acompanhamento mais recente da temática por meio das PNADs.
} 
na sociedade, consubstanciadas em maior busca das mulheres por autonomia individual e satisfação pessoal, além das transformações socioeconômicas vivenciadas por diferentes países que acarretaram elevação das incertezas na vida profissional e, assim, ampliaram a sensação de insegurança em jovens casais.

Mas tais autores também apontam a elevação do capital humano médio das mulheres como outro elemento indutor da decisão de adiar a maternidade (BILLARI; LIEFBROER; PHILIPOV, 2006). Como mostraram Ní Bhrolcháin e Beaujouan (2012), a partir de dados da Grã-Bretanha e França, isso ocorreria tanto pelo efeito direto de que enquanto a jovem está matriculada no ensino continuado seu interesse no matrimônio ou na maternidade é baixo como pelo fato de a obtenção de elevado nível educacional - ou seja, sair do processo de formação escolar em idade mais avançada - estar relacionada à maior postergação da maternidade. Esse último fato pode evidenciar que mulheres com capital humano elevado buscam por mais autonomia e satisfação individual em atividades concorrentes ou não complementares à maternal (ZALDI; MORGAN, 2017), ou que utilizam métodos contraceptivos com regularidade (BONGAARTS, 1987), sendo que tais fatores se relacionam. Afinal, a disseminação do uso da pílula contraceptiva, principalmente a partir da década de 1960, facultou às mulheres o controle sobre sua fecundidade (GOLDIN; KATZ, 2002; BAILEY, 2006). Adicionalmente, para Lee e Gramotnev (2006), entre as possíveis motivações pelas quais algumas mulheres optariam por não ter filhos, está a falta de interesse em relacionamentos tradicionais estabelecidos com os homens, em parte pela condição socioeconômica.

Nesse contexto, muito da decisão de quando realizar o primeiro evento de maternidade passaria a estar relacionada ao planejamento da carreira profissional da mulher, considerando que aquele é um fator com impactos negativos sobre essa. Tais efeitos ocorreriam tanto via a diminuição do acúmulo de capital humano no período pré-maternidade quanto pelas interrupções ou exigências de flexibilidade que a maternidade provocaria na atividade profissional das mulheres (KAHN; LANGE, 2014).

Buckles (2008) contextualiza o fenômeno da postergação da maternidade enquanto um esforço que as mulheres têm feito para compatibilizarem seus anseios profissionais com o de desenvolverem uma família. Segundo a autora, há um nítido trade-off nesses dois objetivos, dadas as evidências de que a ocorrência de maternidade nos primeiros anos de vida profissional das mulheres resulta em menores salários e ascensão no mercado laboral. Isso indica a existência de uma espécie de prêmio pelo adiamento da maternidade, conforme mensurado por Miller (2009) e Amuedo-Dorantes e Kimmel (2005). Buckles (2008) também mostra a importância do nível educacional e da atividade profissional para a decisão de adiamento das mulheres. Sua conclusão é pela importância do acúmulo de capital humano para a definição do prêmio do adiamento.

Mills et al. (2011) seguem na mesma linha ao revisarem diversos estudos sobre os motivos da postergação da maternidade e o seu impacto na taxa de fecundidade dos países desenvolvidos. Para os autores, com a maior possibilidade de a mulher ingressar no mercado laboral ao mesmo tempo que esse passou a ter um viés mais forte para os 
trabalhadores com maior nível de capital humano, o custo de oportunidade da maternidade durante a juventude e, portanto, antes da conclusão da carga de educação formal se tornou mais elevado. De fato, tanto as exigências de aquisição de educação superior quanto os cuidados maternais são fortemente intensivos em tempo. Assim, a partir da década de 1960, a cada geração de mulheres foi se tornando mais premente nos países desenvolvidos compatibilizar a opção maternal e a busca de sucesso na carreira profissional (BREWSTER; RINDFUSS, 2000).

Afinal, segundo Miller (2009), ao contrário de cor, etnia e capacidade genética inata, a idade materna no primeiro filho reflete uma escolha por parte das mulheres que podem responder a incentivos financeiros, normas culturais e ambiente político. Gustafsson (2001) e Buckles (2008), por exemplo, destacam como o nível educacional e a condição socioeconômica das mulheres afetam o cálculo referente ao custo de oportunidade de se ter filhos, fazendo com que a "punição pela maternidade" seja diretamente proporcional ao nível de capital humano acumulado pelas mulheres. Ou, analisando de outro ângulo, as mulheres de maior nível socioeconômico e educacional inferem que terão um prêmio salarial se postergarem a maternidade e dedicarem-se integralmente à carreira profissional (AMUEDO-DORANTES; KIMMEL, 2005; MILLER, 2009).

Nesse contexto, a divisão sexual do trabalho doméstico, relacionado aos cuidados do lar e dos filhos, que se mantém relativamente constante, constitui um importante aspecto a ser considerado para a decisão de maternidade (MILLS et al., 2008). Em países com maior igualdade de gênero, retratada em instituições e políticas que buscam conciliar a maternidade e a participação no mercado de trabalho, observa-se um aumento da fecundidade, embora ainda em níveis baixos (ARPINO et al., 2014). Nesse sentido, não ter filhos ou ter menos filhos pode representar uma reação das mulheres ao considerarem as relações culturais de gênero injustas, como a maior parcela do trabalho de cuidados no lar (MCDONALD, 2013).

Por sua vez, evidências para a América Latina, incluindo o Brasil, indicaram redução das taxas de fecundidade e aumento da gravidez mais tardia. Mudanças estruturais importantes têm ocorrido nessas sociedades, como a expansão do sistema educacional, a rápida urbanização, a migração interna das áreas rurais para as urbanas, bem como ampliação de políticas públicas em governos mais democráticos (ROSERO-BIXBY et al., 2009; CASTANHEIRA; KOHLER, 2015).

Conforme apontam Miranda-Ribeiro (2007) e Miranda-Ribeiro, Rios-Neto e Carvalho (2013), na década de 1990 ainda acontecia no Brasil um fenômeno de antecipação da maternidade, ou seja, o fenômeno de postergar a maternidade para ingressar no mercado de trabalho ainda não era predominante e, assim, não contribuía para a queda da fecundidade observada no último quarto do século XX. ${ }^{2}$ Ao investigarem os efeitos da ordem de nascimento dos filhos sobre a participação feminina na PEA entre 1992 e 2007, Souza,

\footnotetext{
${ }^{2}$ Miranda-Ribeiro, Rios-Neto e Ortega (2006) encontraram evidências de que as mulheres brancas e com maior nível de escolaridade já davam sinais de entrada na fase de postergação da maternidade nas décadas de 1980 e 1990.
} 
Rios-Neto e Queiroz (2011) observaram que, embora negativo, o efeito do nascimento do primeiro filho na probabilidade de engajamento feminino na PEA decaiu ao longo do período analisado. Por outro lado, o efeito negativo a partir do terceiro filho parece ter se ampliado nos anos 2000. Usando informações dos Censos Demográficos de 1980 a 2010, Miranda-Ribeiro, Garcia e Faria (2019) reconstruíram histórias de nascimento capazes de indicar que o adiamento da maternidade passou a contribuir para o decréscimo da taxa de fecundidade no Brasil já a partir da primeira década do século XXI. Também estimaram medidas de fecundidade e observaram aumento da proporção de mulheres sem filhos ao final do período reprodutivo para todas as macrorregiões brasileiras.

Em suma, o fato de as mulheres tradicionalmente serem as principais responsáveis pelos diversos aspectos envolvidos na parentalidade impôs a elas maiores desafios para o atendimento das demandas exigidas no mercado de trabalho e por seus empregadores. Essas transformações constituem o cenário em que se pode observar tanto a queda da taxa de fecundidade quanto o adiamento da maternidade, transformando a compatibilização entre a decisão de maternidade e o ingresso e empenho feminino na vida profissional cada vez mais relevante para a trajetória demográfica futura dos países. Portanto, essa literatura sugere que a dinâmica demográfica ocorre de maneira diferenciada em função, entre outros fatores associados, do nível educacional, do engajamento no mercado de trabalho, da estrutura familiar e das diferenças regionais.

\section{Metodologia}

\section{Dados e método}

Buscando caracterizar os fatores associados ao adiamento da maternidade no Brasil, nesse trabalho foram usadas informações da Pesquisa Nacional por Amostras de Domicílio (PNAD), realizada pelo Instituto Brasileiro de Geografia e Estatística (IBGE), para o período de 1992 até 2015. A justificativa para o início em 1992 é que a partir desse ano foram introduzidas, de forma regular, perguntas sobre a fecundidade; já em 2015 a PNAD se encerrou e a nova versão, PNAD Contínua, deixou de incorporar tais informações. A amostra é composta por mulheres em idade reprodutiva de 15 a 49 anos e que responderam adequadamente às questões sobre fecundidade e demais informações utilizadas no presente trabalho.

Para analisar o adiamento da maternidade, foram consideradas as mulheres que estão expostas a esse fenômeno, aquelas sem filho e aquelas com apenas um filho menor de um ano, ou seja, que tiveram parturição de ordem 1. Note-se que ter tido o primeiro filho é uma variável que, para ser construída, depende de a mulher ter um filho menor de um ano e que sua ordem de parturição seja igual a 1 .

Para obter a expansão de cada observação da amostra, emprega-se sempre a última versão dos pesos disponibilizados na pesquisa. E, com intuito de manter a homogeneidade temporal nos dados, a partir de 2004 são desconsiderados os dados referentes à área 
rural da região Norte, pois no período anterior tal área não estava coberta pela pesquisa. Portanto, conforme o objetivo do presente trabalho, com as exclusões e após a eliminação das observações com alguma informação não declarada, chega-se a uma amostra de 827.840 mulheres no acumulado das PNADs de 1992 a 2015, sendo que no primeiro ano, em 1992, havia 33.316 mulheres e, em 2015, um total de 38.255 , sem filhos ou com filho menor de um ano.

Adotou-se o método da análise de sobrevivência para estimar a postergação da maternidade. Assim, é realizada a análise de sobrevivência buscando identificar o perfil das mulheres, ou seja, as características daquelas que estão sobrevivendo sem filhos ou adiando seu primeiro filho. Portanto, para captar o fenômeno de adiamento da maternidade são consideradas apenas as mulheres sem filhos e aquelas que falharam, ou seja, tiveram filho no último ano ou com filhos menores de um ano. De acordo com Greene (2018) e Latimee (2012), na análise de sobrevivência, a variável a ser examinada é o tempo decorrido até que algum determinado evento ocorra. 0 evento em discussão é o tempo que a mulher sobrevive sem filhos. Esse tempo que a mulher deixa de ter filhos é o enfoque da pesquisa. Por exemplo, conforme a literatura empírica discutida na seção anterior, quanto maior a escolaridade da mulher, espera-se um maior tempo de falha ou maior sobrevivência na condição sem filhos.

Para os modelos de sobrevivência não paramétricos não existe suposição de distribuição de probabilidade para o tempo de sobrevivência. Estes modelos têm caráter basicamente descritivo e podem ser utilizados para auxiliar na escolha do modelo paramétrico adequado. 0 estimador de Kaplan-Meier (KM) é um estimador não paramétrico da função de sobrevivência e pode ser obtido ordenando os valores de duração de forma crescente.

Os limites de cada segmento de intervalo de tempo correspondem ao tempo em que houve eventos. 0 estimador de KM é definido como:

$\hat{S}(t)=\prod_{j, t \leq t}\left(1-\frac{d_{j}}{n_{j}}\right)$

Em que $j$ corresponde aos tempos de sobrevivência ordenados, $t_{1}<t_{2}<t_{3}, \ldots t_{j}$, sendo $n_{j}$ o número de indivíduos que estão em risco de não terem filhos em cada tempo $t_{j}$, e $d_{j}$ é o número de indivíduos que não tiveram filhos no tempo $t_{j}$. Este estimador tem como característica ser uma função escada, em que os "degraus" ocorrem nos instantes de tempo em que ocorrem as falhas, em que há tantos intervalos quantos forem os números de falhas distintas. Por sua vez, os modelos paramétricos são assim definidos porque baseiam-se na suposição de uma distribuição de probabilidade para o tempo de sobrevivência e são chamados de modelos probabilísticos, os quais podem ser representados por: Lnt $t_{i}=x^{\prime} \beta+u_{i}$

As variáveis explicativas estão incluídas no vetor $x$, relacionadas às características pessoais das mulheres, como cor ou raça e anos de estudo, bem como sua condição na família e no mercado de trabalho, e à localidade da residência, conforme o Quadro 1. 
Além das especificações empíricas para alguns anos selecionados, adicionalmente são estimadas três especificações para os dados empilhados, considerando todos os anos da PNAD de 1992 até 2015. Enquanto na primeira especificação são incluídas as mesmas variáveis já definidas, na segunda estimativa são acrescentadas variáveis binárias para as coortes de nascimento das mulheres, buscando captar as mudanças entre as gerações. São consideradas 11 coortes para as nascidas de 1950 até 1954, de 1955 até 1959 , de 1960 até 1964 , de 1965 até 1969 , de 1970 até 1974 , de 1975 até 1979 , de 1980 até 1984 , de 1985 até 1989, de 1990 até 1994, de 1995 até 1999 e de 2000 até 2004, cuja referência são as nascidas de 1940 até 1949.

QUADRO 1

Descrição das variáveis binárias explicativas utilizadas na regressão

\begin{tabular}{|c|c|}
\hline Variável & Descrição \\
\hline \multicolumn{2}{|l|}{ Cor ou raça } \\
\hline Branca & 1 para cor ou raça branca ou amarela; 0 em caso contrário \\
\hline \multicolumn{2}{|l|}{ Anos de estudo } \\
\hline 1 a 3 & 1 para anos de estudo de 1 a 3; 0 caso contrário \\
\hline 4 a 7 & 1 para anos de estudo de 4 a 7; 0 caso contrário \\
\hline 8 a 10 & 1 para anos de estudo de 8 a 10; 0 caso contrário \\
\hline 11 a 14 & 1 para anos de estudo de 11 a 14; 0 caso contrário \\
\hline 15 ou mais & 1 para 15 ou mais anos de estudo; 0 caso contrário \\
\hline \multicolumn{2}{|l|}{ Estado conjugal } \\
\hline Casada & 1 para mulheres com cônjuge; 0 caso contrário \\
\hline \multicolumn{2}{|c|}{ Participação no mercado de trabalho } \\
\hline PEA & 1 quando participa do mercado de trabalho; 0 caso contrário \\
\hline \multicolumn{2}{|c|}{ Condição na família } \\
\hline Chefe & 1 quando é a pessoa de referência na família; 0 caso contrário \\
\hline \multicolumn{2}{|l|}{ Região } \\
\hline Nordeste & 1 se reside na região Nordeste; 0 caso contrário \\
\hline Sudeste & 1 se reside na região Sudeste; 0 caso contrário \\
\hline Sul & 1 se reside na região Sul; 0 caso contrário \\
\hline Centro-Oeste & 1 se reside na região Centro-Oeste; 0 caso contrário \\
\hline \multicolumn{2}{|l|}{ Localidade } \\
\hline Metropolitana & 1 se reside em região metropolitana; 0 caso contrário \\
\hline \multicolumn{2}{|l|}{ Área } \\
\hline Urbana & 1 se reside em área urbana; 0 caso contrário \\
\hline \multicolumn{2}{|c|}{ Coorte de nascimento } \\
\hline Coorte_50_54 & 1 se nasceu de 1950 até 1954; 0 caso contrário \\
\hline Demais coortes & 1 se nasceu na respectiva coorte; 0 caso contrário \\
\hline \multicolumn{2}{|l|}{ Ciclo econômico } \\
\hline 1993 & 1 se participou da pesquisa em 1993; 0 caso contrário \\
\hline Demais anos & 1 se participou da respectiva pesquisa; 0 caso contrário \\
\hline
\end{tabular}

Fonte: Elaboração dos autores.

Ademais, buscando controlar o efeito do ciclo econômico do período, bem como captar mudanças de longo prazo no comportamento das mulheres, são incorporadas, na terceira 
estimativa, variáveis binárias para cada ano da pesquisa, de 1993 até 2015, tomando o ano inicial de 1992 como referência. Assim, ao se incluírem essas variáveis binárias, é retirado o efeito do ciclo econômico nos demais coeficientes, de tal forma que as estimativas para as variáveis já incluídas anteriormente se tornam mais robustas. ${ }^{3}$

\section{Evidências do adiamento da maternidade no Brasil, de 1992 até 2015}

Conforme mostra o Gráfico 1, a entrada da mulher na maternidade tem sido adiada no Brasil, quando se observa a idade média da mulher com nascimentos de primeira ordem, considerando filhos com menos de um ano. Essa idade média aumentou de 22,5 anos, em 1992, para 24,6, em 2015. ${ }^{4}$ Porém, tal fato pode estar sendo influenciado pela mudança na estrutura etária no país, com a população mais envelhecida ao final do período analisado. Buscando detalhar melhor esse processo e verificar em qual faixa etária há redução maior dos nascimentos de primeira ordem, no Gráfico 2 são apresentadas informações apenas dos anos extremos, 1992 e 2015, com a proporção de mulheres que entraram na maternidade. Seguindo a metodologia, no trabalho são consideradas as mulheres com nascimentos de primeira ordem e sem filhos, as quais são o denominador da proporção obtida no Gráfico 2. Por fim, para compreender ainda mais o comportamento das mulheres que estão adiando a primeira maternidade, são acrescentadas, no Gráfico 3, as informações de todos os anos da pesquisa, de 1992 a 2015, com a coorte de nascimento, além da idade.

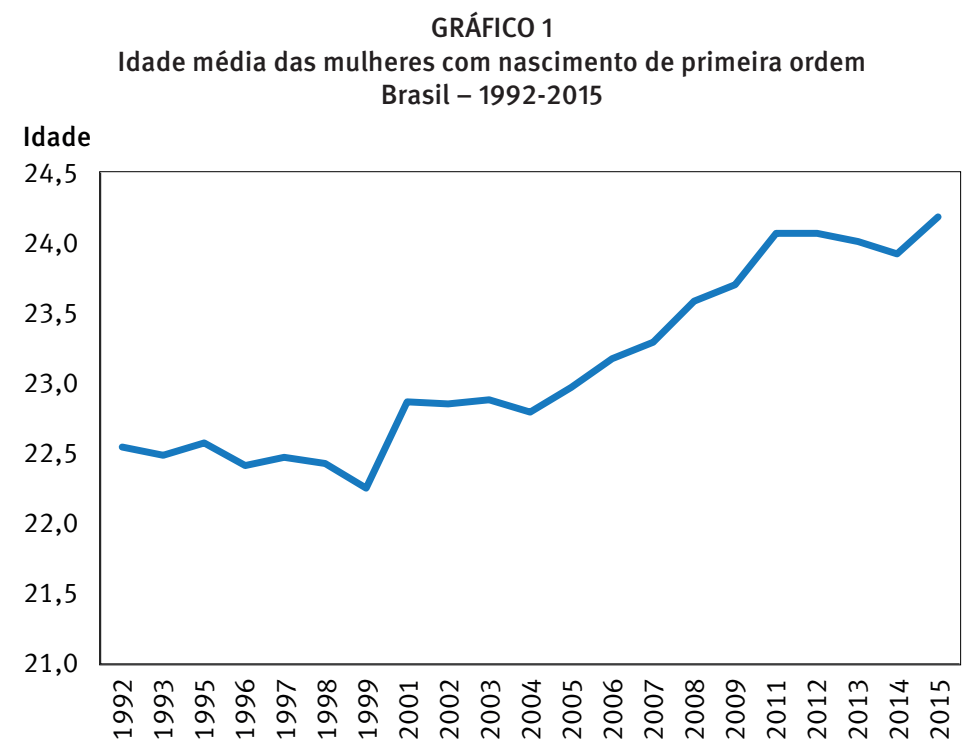

Fonte: IBGE. PNAD. Elaboração dos autores.

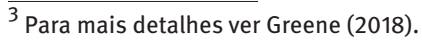

${ }^{4}$ Foi utilizada a média aritmética para as idades das mulheres com nascimentos de primeira ordem dividida pelo total de observações em cada ano.
} 
GRÁFICO 2

Proporção (1) de mulheres com nascimentos de primeira ordem, segundo idade Brasil - 1992-2015

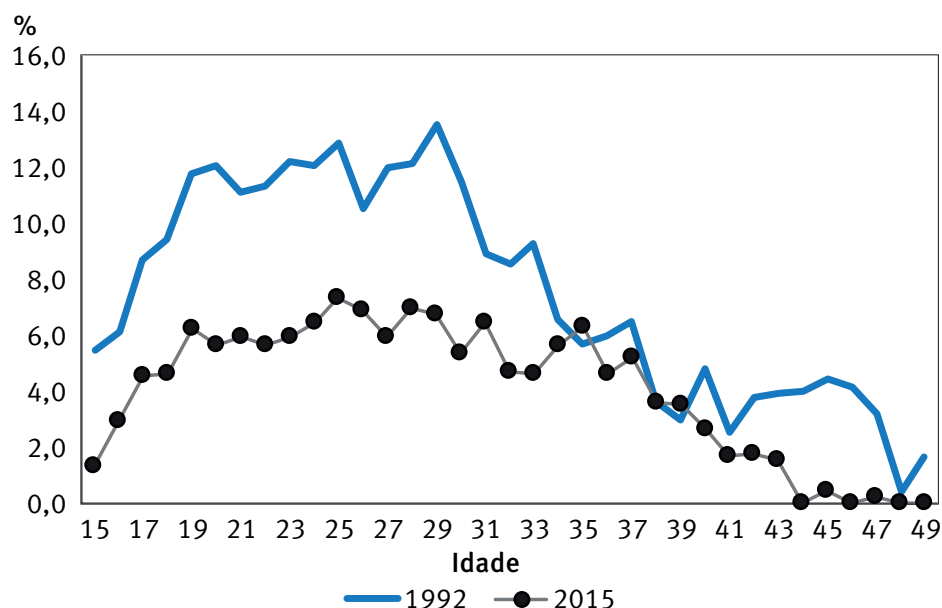

Fonte: IBGE. PNAD. Elaboração dos autores.

(1) Proporção no total das mulheres sem filhos e daquelas com nascimento de primeira ordem, cujos filhos têm menos de um ano.

\section{GRÁFICO 3}

Proporção (1) de mulheres com nascimentos de primeira ordem, por idade, segundo coorte de nascimento Brasil - 1992-2015

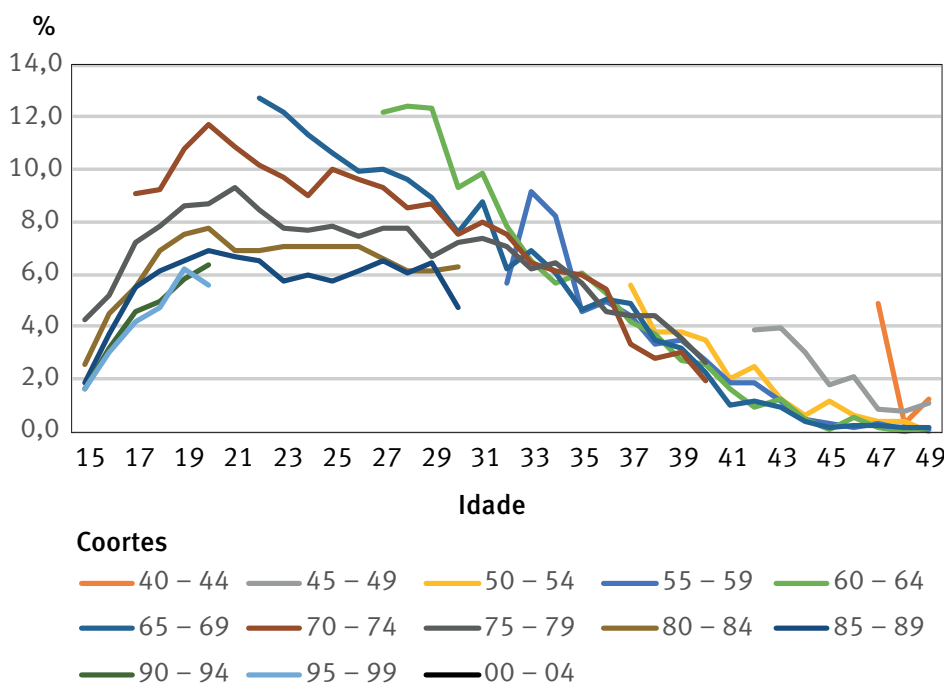

Fonte: IBGE. PNAD. Elaboração dos autores.

(1) Proporção no total das mulheres sem filhos e daquelas com nascimento de primeira ordem, cujos filhos têm menos de um ano.

Assim, observa-se que, em 1992, uma maior proporção de mulheres teve o seu primeiro filho na faixa etária de 20 a 29 anos, com os percentuais oscilando entre $9 \%$ e $12 \%$ em cada idade, sendo tal máximo verificado aos 29 anos, conforme mostra o Gráfico 2. A partir do início dos 30 anos nota-se uma tendência de redução desse percentual até o final do ciclo reprodutivo. Na comparação com 2015, podem ser destacados cinco aspectos. 
Inicialmente verifica-se a redução média do percentual de mulheres na condição de primeiro filho, provocando um achatamento da curva de distribuição, o que está de acordo com a redução da taxa de fecundidade total.

Um segundo aspecto é que as duas curvas estão em níveis próximos apenas na segunda metade dos 30 anos, sugerindo que as mulheres expostas ao evento de primeira maternidade, em 2015, estão entrando na maternidade em idades mais avançadas, mas não muito além da faixa etária dos 30 anos. Esses resultados estão de acordo com os trabalhos de Miranda-Ribeiro (2007) e Miranda-Ribeiro, Rios-Neto e Carvalho (2013), que observaram antecipação da maternidade na década de 1990 no Brasil, embora Miranda-Ribeiro, Garcia e Faria (2019) já encontrem evidências do adiamento da entrada na maternidade na primeira década do século XXI no país.

Outro aspecto no formato das curvas em "U" invertido é o início da sua parte decrescente refletindo a queda da proporção de mulheres entrando na maternidade, do início dos 30 anos, em 1992, para os 35 anos, em 2015. Adicionalmente, nota-se que aumenta 0 número de mulheres que optam por não ter filhos, pois em 2015 o percentual de mulheres com filhos se reduz tanto no início quanto no final do ciclo reprodutivo, conquanto essa queda seja mais significativa no início desse ciclo. Por fim, enquanto em 1992 a proporção de mulheres com nascimento de primeira ordem era maior entre as mais jovens, de 15 a 17 anos, do que para as mais velhas, a partir dos 35 anos, em 2015 são as mais velhas que têm as maiores proporções, quando comparadas com as mais jovens. Portanto, na comparação entre 1992 e 2015 para nascimentos de primeira ordem, verifica-se declínio nos níveis de fecundidade tanto nos primeiros anos reprodutivos quanto nos finais, mas ressalta-se que a partir dos 35 anos a proporção de entradas na maternidade passa a ser maior do que nos anos iniciais, refletindo uma mudança no comportamento reprodutivo das mulheres.

o Gráfico 3, da mesma forma que o Gráfico 2, tem formato de "U” invertido, indicando um crescimento dos nascimentos de primeira ordem até em torno dos 30 anos e depois uma queda nos anos seguintes. No entanto, no Gráfico 3, com todos os anos incluídos, é possível observar o comportamento das gerações de mulheres. Verifica-se que as coortes mais recentes, tanto no início quanto nas fases mais avançadas do ciclo reprodutivo, atingem percentuais mais baixos, ou seja, uma menor proporção entra na maternidade. Porém, durante os 30 anos, especialmente ao final, as coorte mais jovens e mais velhas apresentam um comportamento similar.

Desse modo, verifica-se que, em parte, isso reflete o fato de a fecundidade das muIheres adolescentes e daquelas na faixa etária dos 20 anos ter diminuído, com maior proporção de mulheres jovens sem filhos e nascimentos de primeira ordem em período mais avançado do ciclo reprodutivo das mulheres. Ou seja, quando acontece o primeiro evento de parturição, a tendência é que seja em períodos mais avançados do ciclo reprodutivo feminino. Adicionalmente, este fato sugere que as mulheres não estão apenas planejando o primeiro filho em idades mais avançadas, mas também estão deixando de ter filhos, conforme alertou Leridon (2004). 
No período analisado, verificam-se mudanças significativas tanto para as mulheres sem filhos quanto para aquelas com filhos menores de um ano. Conforme pode ser observado na Tabela 1, considerando os anos inicial e final do trabalho, a idade média aumentou pouco mais de dois anos, puxada por aquelas na condição de sem filho. Isso pode ser indício da expansão do fenômeno de adiamento da maternidade de 1992 para 2015 no Brasil, captado nos trabalhos de Miranda-Ribeiro (2007), para a década de 1990, e de MirandaRibeiro, Garcia e Faria (2019), para os anos 2000.

Em paralelo, diminuiu a participação das mulheres declaradas como brancas e aumentou a das moradoras em áreas urbanas. Ocorreu ainda um salto no nível de escolaridade independentemente da condição maternal. Se consideradas as mulheres com 11 ou mais anos de estudo, nos níveis 5 e 6 , a porcentagem cresceu de 24,1\%, em 1992, para 61,4\%, em 2015, sinal do aumento de capital humano feminino. Embora não sendo substancial a diferença entre os dois grupos de mulheres, o percentual daquelas com 11 ou mais anos de escolaridade sem filho $(61,4 \%)$ é superior ao das mulheres com primeiro filho $(60,9 \%)$.

Há também uma menor proporção de casadas e mais que dobrou o percentual daquelas na condição de chefe de domicílio, especialmente para as com primeiro filho, cuja ascensão foi de $17,6 \%$ para $29,7 \%$, entre 1992 e 2015 . A participação na PEA permaneceu em torno de $60 \%$, embora se destaque a diferença entre as sem filho (61\%) e as com filho $(47,4 \%)$. Ressalta-se, porém, que as com filho apresentaram uma elevação de 6,5 pontos percentuais na participação ao longo do período. Portanto, a associação negativa entre decisão de maternidade do primeiro filho e a participação no mercado de trabalho parece ter se atenuado.

Por fim, verifica-se que as regiões Sudeste e Nordeste perderam participação relativa em detrimento do Norte e Centro-Oeste. Ademais, chamam a atenção o aumento mais que proporcional das mulheres com primeiro filho no Norte (de 4,4\% para 7,6\%) e a redução daquelas nesta mesma condição no Sudeste (de $42,6 \%$ para $40,3 \%$ ). Possivelmente, isso tem e terá repercussões nas taxas de expansão populacional dessas duas regiões e pode refletir um maior interesse das mulheres da região Sudeste em se dedicarem à carreira profissional.

Portanto, verifica-se que, entre 1992 e 2015, as mulheres foco dessa pesquisa, aquelas sem filhos e com o primeiro filho com menos de um ano de idade, se tornaram menos dependentes da presença masculina para a constituição de família, mas mais escolarizadas, urbanas e participativas no mercado de trabalho. A idade média das mulheres sem filhos e daquelas com o primeiro filho aumentou no período, o que sugere um adiamento da maternidade ou que elas estão optando por não ter filhos. Estas evidências estão de acordo com a literatura abordada sobre a divisão sexual do trabalho, segundo a qual a decisão de maternidade pode constituir uma estratégia ou reação das mulheres à forma desigual das relações e normas de gênero (MILLS et al., 2008; ARPINO et al., 2014; MCDONALD, 2013). Além disso, a redução da gravidez precoce e a gravidez mais tardia são características de países com níveis baixos de fecundidade (ROSERO-BIXBY et al., 2009; CASTANHEIRA; KOHLER, 2015). 
TABELA 1

Idade média e proporção das mulheres sem filhos e com o primeiro filho com idade menor de um ano, segundo variáveis selecionadas

Brasil - 1992-2015

\begin{tabular}{|c|c|c|c|c|c|c|c|c|c|}
\hline \multirow[b]{2}{*}{ Variáveis } & \multicolumn{3}{|c|}{1992} & \multicolumn{3}{|c|}{2015} & \multicolumn{3}{|c|}{ De 1992 até 2015} \\
\hline & Total & $\begin{array}{l}\text { Sem } \\
\text { filho }\end{array}$ & $\begin{array}{l}\text { Primeiro } \\
\text { filho }\end{array}$ & Total & $\begin{array}{l}\text { Sem } \\
\text { filho }\end{array}$ & $\begin{array}{l}\text { Primeiro } \\
\text { filho }\end{array}$ & Total & $\begin{array}{l}\text { Sem } \\
\text { filho }\end{array}$ & $\begin{array}{c}\text { Primeiro } \\
\text { filho }\end{array}$ \\
\hline Idade média & 22,592 & 22,596 & 22,536 & 24,763 & 24,791 & 24,186 & 23,656 & 23,688 & 23,114 \\
\hline \multicolumn{10}{|c|}{ Cor ou raça (\%) } \\
\hline Não branca & 0,436 & 0,437 & 0,425 & 0,513 & 0,510 & 0,571 & 0,461 & 0,459 & 0,497 \\
\hline Branca & 0,564 & 0,563 & 0,575 & 0,487 & 0,490 & 0,429 & 0,539 & 0,541 & 0,503 \\
\hline \multicolumn{10}{|c|}{$\begin{array}{l}\text { Anos de estudo } \\
(\%)\end{array}$} \\
\hline Menos de 1 & 0,069 & 0,069 & 0,077 & 0,023 & 0,023 & 0,014 & 0,034 & 0,034 & 0,030 \\
\hline 1 a 3 & 0,117 & 0,116 & 0,136 & 0,012 & 0,013 & 0,009 & 0,045 & 0,044 & 0,062 \\
\hline 4 a 7 & 0,354 & 0,351 & 0,390 & 0,096 & 0,095 & 0,129 & 0,196 & 0,192 & 0,268 \\
\hline 8 a 10 & 0,219 & 0,222 & 0,182 & 0,254 & 0,255 & 0,239 & 0,264 & 0,266 & 0,236 \\
\hline 11 a 14 & 0,191 & 0,192 & 0,169 & 0,453 & 0,453 & 0,457 & 0,361 & 0,363 & 0,327 \\
\hline 15 ou mais & 0,050 & 0,050 & 0,045 & 0,161 & 0,161 & 0,152 & 0,100 & 0,101 & 0,077 \\
\hline
\end{tabular}

\begin{tabular}{|c|c|c|c|c|c|c|c|c|c|}
\hline \multicolumn{10}{|l|}{$\begin{array}{l}\text { Estado } \\
\text { conjugal (\%) }\end{array}$} \\
\hline Casada & 0,737 & 0,732 & 0,798 & 0,674 & 0,670 & 0,753 & 0,698 & 0,696 & 0,744 \\
\hline Não casada & 0,263 & 0,268 & 0,202 & 0,326 & 0,330 & 0,247 & 0,302 & 0,304 & 0,256 \\
\hline \multicolumn{10}{|l|}{$\begin{array}{l}\text { Participação no } \\
\text { mercado de } \\
\text { trabalho (\%) }\end{array}$} \\
\hline PEA & 0,600 & 0,614 & 0,419 & 0,604 & 0,611 & 0,474 & 0,611 & 0,620 & 0,459 \\
\hline Não PEA & 0,400 & 0,386 & 0,581 & 0,396 & 0,389 & 0,526 & 0,389 & 0,380 & 0,541 \\
\hline \multicolumn{10}{|l|}{$\begin{array}{l}\text { Condição na } \\
\text { família (\%) }\end{array}$} \\
\hline Chefe & 0,052 & 0,042 & 0,176 & 0,125 & 0,116 & 0,297 & 0,086 & 0,076 & 0,255 \\
\hline $\begin{array}{l}\text { Cônjuge ou } \\
\text { outra }\end{array}$ & 0,948 & 0,958 & 0,824 & 0,875 & 0,884 & 0,703 & 0,914 & 0,924 & 0,745 \\
\hline \multicolumn{10}{|l|}{ Região (\%) } \\
\hline Norte & 0,039 & 0,038 & 0,044 & 0,064 & 0,063 & 0,076 & 0,054 & 0,053 & 0,068 \\
\hline Nordeste & 0,292 & 0,292 & 0,293 & 0,273 & 0,271 & 0,317 & 0,280 & 0,279 & 0,307 \\
\hline Sudeste & 0,462 & 0,465 & 0,426 & 0,449 & 0,452 & 0,403 & 0,457 & 0,460 & 0,407 \\
\hline Sul & 0,144 & 0,143 & 0,164 & 0,136 & 0,137 & 0,122 & 0,140 & 0,140 & 0,139 \\
\hline Centro-Oeste & 0,063 & 0,062 & 0,072 & 0,078 & 0,077 & 0,082 & 0,070 & 0,069 & 0,079 \\
\hline \multicolumn{10}{|l|}{ Localidade (\%) } \\
\hline Metropolitana & 0,354 & 0,355 & 0,334 & 0,356 & 0,359 & 0,304 & 0,355 & 0,358 & 0,308 \\
\hline $\begin{array}{l}\text { Não } \\
\text { metropolitana }\end{array}$ & 0,646 & 0,645 & 0,666 & 0,644 & 0,641 & 0,696 & 0,645 & 0,642 & 0,692 \\
\hline \multicolumn{10}{|l|}{ Área (\%) } \\
\hline Urbana & 0,829 & 0,830 & 0,816 & 0,901 & 0,903 & 0,864 & 0,878 & 0,879 & 0,849 \\
\hline Rural & 0,171 & 0,0170 & 0,184 & 0,099 & 0,097 & 0,136 & 0,122 & 0,121 & 0,151 \\
\hline
\end{tabular}

Fonte: IBGE. PNAD. Elaboração dos autores. 


\section{Fatores associados ao adiamento da maternidade no Brasil}

Essa seção evidencia o adiamento da maternidade no Brasil a partir da análise de sobrevivência, primeiramente com o estimador de Kapler-Meier e, posteriormente, com a estimação de modelos de regressão paramétricos, buscando caracterizar o tempo até a falha, ou seja, ter o nascimento de primeira ordem, bem como os fatores associados a esse evento. Os resultados para o método não paramétrico de Kapler-Meier, para 1992 e 2015, são apresentados no Gráfico 4. No eixo horizontal do gráfico da função de sobrevivência está o tempo em anos de idade que a mulher permanece sem filhos e, no eixo vertical, está a probabilidade de sobrevivência, ou permanência, nessa condição. Observa-se que as falhas se iniciam aos 15 anos, primeiro decrescendo rapidamente, na faixa de 15 a 30 anos, e posteriormente de forma mais lenta e, ao final, após os 40 anos, estabilizam-se, indicando que fica mais difícil sair da condição de sem filho, o que está relacionado ao ciclo reprodutivo feminino.

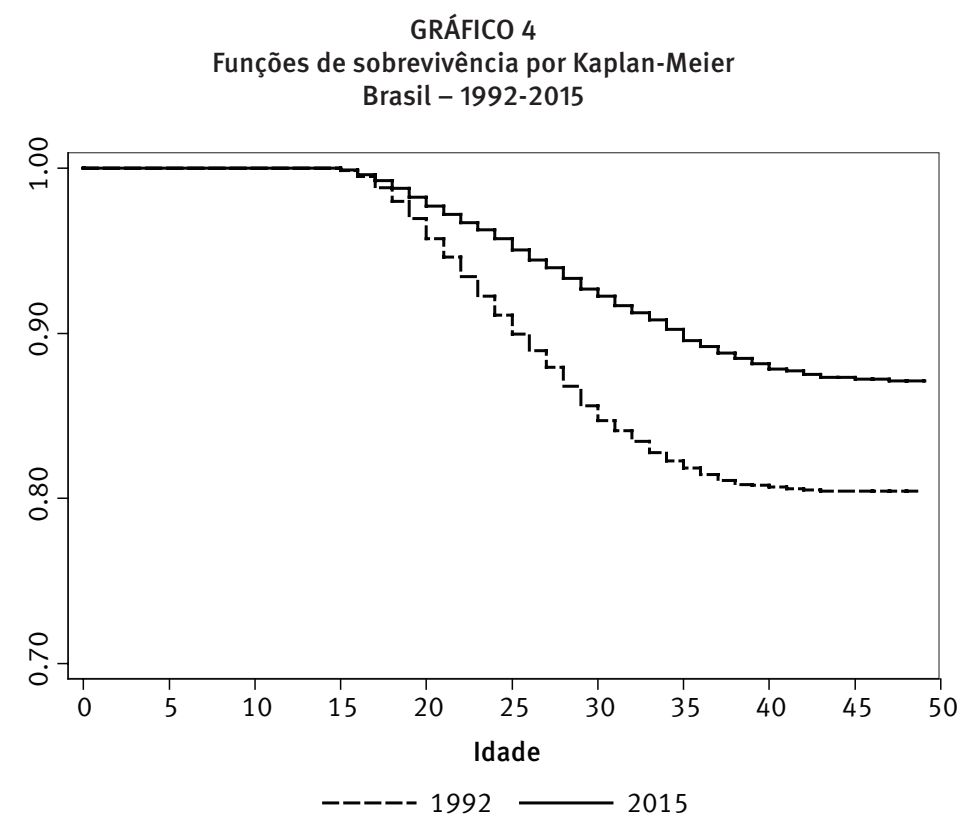

Fonte: IBGE. PNAD. Elaboração dos autores.

O comportamento dessa relação altera-se do início para o final do período analisado, sugerindo a postergação da maternidade e o aumento da proporção de mulheres que sobrevivem sem filhos, fatores que contribuem para a redução do nível de fecundidade. Em 1992, a probabilidade de as mulheres de 15 a 24 anos sobreviverem sem filhos é superior a $90 \%$ em média, porém, essa probabilidade diminui com o passar dos anos, chegando a $79,5 \%$ aos 49 anos. Já em 2015, a probabilidade de sobrevivência é bem maior em todas as faixas de idade, sendo seu menor valor aos 49 anos, quando atinge $85,5 \%$. 
Considerando uma análise multivariada, são estimados os modelos paramétricos que verificam a significância e importância dos fatores associados à probabilidade de sobrevivência sem filhos, ou seja, à probabilidade de a mulher permanecer sem ter filhos naquele ano, conforme mostra a Tabela 2. As estimativas paramétricas das funções de sobrevivência são realizadas com base nas distribuições Weibull, exponential, log normal, log logística e gama. Porém, apresentam-se apenas os resultados obtidos com a distribuição gama, selecionada a partir do critério de Akaike (AIC) e do valor log likehood.

TABELA 2

Estimativas do modelo paramétrico Brasil - 1992-2015

\begin{tabular}{|c|c|c|c|c|c|c|c|}
\hline \multirow{2}{*}{ Variáveis } & \multirow{2}{*}{$\begin{array}{c}1992 \\
(1)\end{array}$} & \multirow{2}{*}{$\begin{array}{c}1995 \\
(2)\end{array}$} & \multirow{2}{*}{$\begin{array}{c}2005 \\
\text { (3) }\end{array}$} & \multirow{2}{*}{$\begin{array}{c}2015 \\
(4)\end{array}$} & \multicolumn{3}{|c|}{ De 1992 até 2015} \\
\hline & & & & & (5) & (6) & (7) \\
\hline \multicolumn{8}{|l|}{ Anos de estudos } \\
\hline 1 a 3 & 0,963 & 0,981 & $0,844^{\star * \star}$ & 1,056 & $0,922^{\star \star \star}$ & $0,891^{\star \star \star}$ & $0,964^{\star \star \star}$ \\
\hline $4 \mathrm{a} 7$ & 0,977 & 0,986 & $0,781^{\star \star \star}$ & $0,881^{\star \star}$ & $0,905^{\star \star \star}$ & $0,888^{\star \star \star}$ & $0,956^{\star \star \star}$ \\
\hline 8 a 10 & $1,060^{\star \star}$ & $1,051^{\star \star}$ & $0,830^{\star \star \star}$ & 0,934 & $0,957^{\star \star \star}$ & $0,965^{\star \star \star}$ & $0,976^{\star \star \star}$ \\
\hline 11 a 14 & $1,203^{\star \star \star}$ & $1,241^{\star \star \star}$ & 0,979 & $1,093^{*}$ & $1,125^{\star \star \star}$ & $1,116^{\star \star \star}$ & $1,003^{\star \star \star}$ \\
\hline 15 ou mais & $1,392^{\star \star \star}$ & $1,477^{\star \star \star}$ & $1,215^{\star \star \star}$ & $1,365^{\star \star \star}$ & $1,391^{\star \star \star}$ & $1,257^{\star \star \star}$ & $1,012^{\star \star \star}$ \\
\hline Branca & 0,991 & $1,014^{\star \star \star}$ & $1,011^{\star \star \star}$ & $1,033^{\star \star \star}$ & $1,011^{\star \star \star}$ & $0,987^{\star \star \star}$ & $1,004^{\star \star \star}$ \\
\hline Casada & 0,842 & 0,815 & $0,885^{\star}$ & $0,956^{\star \star}$ & $0,918^{\star \star \star}$ & $0,889^{\star \star \star}$ & $0,961^{\star \star \star}$ \\
\hline Chefe da família & $0,743^{\star \star \star}$ & $0,695^{\star \star \star}$ & $0,757^{\star \star \star}$ & $0,906^{\star \star \star}$ & $0,822^{\star \star \star}$ & $0,805^{\star \star \star}$ & $0,902^{\star \star \star}$ \\
\hline PEA & $1,138^{\star \star \star}$ & $1,143^{\star \star \star}$ & $1,157^{\star \star \star}$ & $1,129^{\star \star \star}$ & $1,131^{\star \star \star}$ & $1,132^{\star \star \star}$ & $1,056^{\star \star \star}$ \\
\hline Urbana & 0,997 & 1,018 & $1,022^{\star}$ & $1,028^{\star \star}$ & $1,017^{\star \star \star}$ & $1,019^{\star \star \star}$ & $1,006^{\star \star \star}$ \\
\hline Metropolitana & $1,019^{\star}$ & 1,014 & $1,029^{\star \star \star}$ & $1,028^{\star \star \star}$ & $1,027^{\star \star \star}$ & $1,017^{\star \star \star}$ & $1,009^{\star \star \star}$ \\
\hline Nordeste & 1,007 & 1,084 & 1,015 & $1,010^{\star \star \star}$ & $1,027^{\star \star \star}$ & $1,022^{\star \star \star}$ & $1,008^{\star \star \star}$ \\
\hline Sudeste & $1,053^{\star \star \star}$ & $1,088^{\star \star \star}$ & $1,042^{\star \star \star}$ & $1,037^{\star \star \star}$ & $1,036^{\star \star \star}$ & $1,029^{\star * \star}$ & $1,010^{\star \star \star}$ \\
\hline Sul & $1,014^{\star \star \star}$ & $1,033^{\star \star \star}$ & $1,041^{\star \star \star}$ & $1,026^{\star \star \star}$ & $1,021^{\star \star \star}$ & $1,017^{\star \star \star}$ & $1,006^{\star \star \star}$ \\
\hline Centro-Oeste & $0,996^{\star \star \star}$ & $1,033^{\star * \star}$ & $0,993^{\star \star *}$ & $0,991^{\star \star \star}$ & $1,010^{\star \star \star}$ & $1,004^{* \star *}$ & $1,002^{\star \star \star}$ \\
\hline Coorte_50_54 & & & & & & $0,831^{\star \star \star}$ & $0,824^{\star \star \star}$ \\
\hline Coorte_55_59 & & & & & & $0,691^{\star \star \star}$ & $0,677^{\star \star \star}$ \\
\hline Coorte_60_64 & & & & & & $0,561^{\star \star \star}$ & $0,562^{\star \star \star}$ \\
\hline Coorte_65_69 & & & & & & $0,473^{\star \star \star}$ & $0,469^{\star \star \star}$ \\
\hline Coorte_70_74 & & & & & & $0,399^{\star \star \star}$ & $0,389^{\star \star \star}$ \\
\hline Coorte_75_79 & & & & & & $0,362^{\star \star \star}$ & $0,324^{\star \star \star}$ \\
\hline Coorte_80_84 & & & & & & $0,349^{\star \star \star}$ & $0,272^{\star \star \star}$ \\
\hline Coorte_85_89 & & & & & & $0,334^{\star \star \star}$ & $0,226^{\star \star \star}$ \\
\hline Coorte_90_94 & & & & & & $0,323^{\star \star \star}$ & $0,188^{\star \star \star}$ \\
\hline Coorte_95_99 & & & & & & $0,316^{\star \star \star}$ & $0,157^{\star \star \star}$ \\
\hline Coorte_00_04 & & & & & & $0,331^{\star \star \star}$ & $0,140^{\star \star \star}$ \\
\hline Ano & Não & Não & Não & Não & Não & Não & Sim \\
\hline Constante & $28,233^{\star \star \star}$ & $27,213^{\star \star \star}$ & $31,999 * \star \star$ & $24,558^{\star \star \star}$ & $26,160^{\star \star \star}$ & $89,975^{\star \star \star}$ & $61,525^{\star \star \star}$ \\
\hline Observações & 33.316 & 35.719 & 43.510 & 38.255 & 827.840 & & \\
\hline
\end{tabular}

Fonte: IBGE. PNAD. Elaboração dos autores.

*** estimativas significativas a $1 \%$; ${ }^{\star *}$ estimativas significativas a $5 \%$; * estimativas significativas a $10 \%$. 
Os resíduos de Cox-Snell indicam bom ajuste do modelo com a distribuição gama, cujos coeficientes estimados estão na forma de razão de risco. ${ }^{5}$ São expostas sete especificações: (1) uma estimativa para o ano inicial; (2 e 3) duas para anos intermediários; (4) uma para o ano final da análise; e (5, 6 e 7) três estimativas considerando os dados concernentes a todo o período de 1992 a 2015, sendo que nas duas últimas especificações (6 e 7) são incluídas variáveis binárias para cada coorte de nascimento, considerando as nascidas nos anos 1940 como de referência (Tabela 2).

Na última especificação são inseridas variáveis binárias para cada ano da pesquisa, tomando como base 1992, para captar mudanças no ciclo econômico e no comportamento demográfico de longo prazo. Na comparação entre as três especificações com todos os anos empilhados (5, 6 e 7), nota-se semelhança no impacto, positivo ou negativo, dos fatores associados ao adiamento da maternidade, indicando que as estimativas são robustas.

As estimativas incluindo os efeitos coorte ( 6 e 7) indicam que as mais jovens sobrevivem menos sem filhos ou têm um tempo de falha menor, o que pode ser explicado pelo seu momento no ciclo reprodutivo. Por outro lado, aquelas que adiam a maternidade, nas coortes mais antigas, sobrevivem mais sem filhos, fato provavelmente associado às maiores dificuldades de se ter um filho conforme avança a idade reprodutiva da mulher, como salientou Miller (2009). Por sua vez, com a inclusão das binárias de ano, na especificação (7), a magnitude dos demais coeficientes é reduzida, indicando que, ao longo do período, ocorreram mudanças significativas que atingiram todas as mulheres. Assim, os coeficientes estimados sugerem que as mulheres estão sobrevivendo mais sem filhos: $134,0 \%$ a mais em 2015 em relação a 1992, enquanto em 1993 esse percentual era 3,7\%, o que sugere que há um processo de adiamento da maternidade no Brasil, conforme mostra o Gráfico $5 .{ }^{6}$

De acordo com as estimativas apresentadas na Tabela 2, os anos de estudo constituem um determinante relevante para a probabilidade de sobrevivência, portanto, para as chances de a mulher permanecer na condição de sem filho. As estimativas significativas sugerem que, em média, o tempo de falha para as mulheres entrarem na maternidade é menor do que um para as mulheres nos níveis iniciais de escolaridade e superior à unidade para aquelas com mais anos de escolaridade, considerando como categoria de referência as mulheres analfabetas ou com menos de um ano de estudo. Assim, no caso da especificação (5), com informações de 1992 até 2015, enquanto as mulheres com 1 até 3 anos de estudos têm $7,8 \%$ menos chances de sobreviverem sem filhos, aquelas com 15 anos ou mais de estudos têm $39,1 \%$ mais chances de permanecerem sem filhos. Em outras palavras, é possível dizer

\footnotetext{
$\overline{5}$ Os valores na Tabela 2 estão na forma de razão de risco. É possível transformar os valores encontrados para as razões de risco em semielasticidades do risco com relação às variáveis. Para tanto, é necessário subtrair 1 da estimativa da razão de risco e multiplicar o resultado por 100.

${ }^{6}$ Conforme pode ser observado no Gráfico 5, os coeficientes estimados apresentam uma tendência crescente no período, evidenciando a maior sobrevivência sem filhos, cujos valores são: 1,037 (1993), 1,117 (1995), 1,161 (1996), 1,205 (1997), 1,246 (1998), 1,288 (1999), 1,395 (2001), 1,447 (2002), 1,500 (2003), 1,549 (2004), 1,608 (2005), 1,669 (2006), 1,743 (2007), 1,807(2008), 1,874 (2009), 2,034 (2011), 2,111 (2012), 2,185 (2013), 2,254 (2014) e 2,344 (2015). Destaca-se que todos foram estatisticamente significativos.
} 
que as mulheres com um menor nível de escolaridade têm um tempo de falha - idade de entrada na maternidade - inferior ao daquelas com um nível maior de escolaridade.

\section{GRÁFICO 5}

Estimativas dos diferenciais de ano para a sobrevivência à maternidade, em relação ao ano de 1992 Brasil - 1993-2015

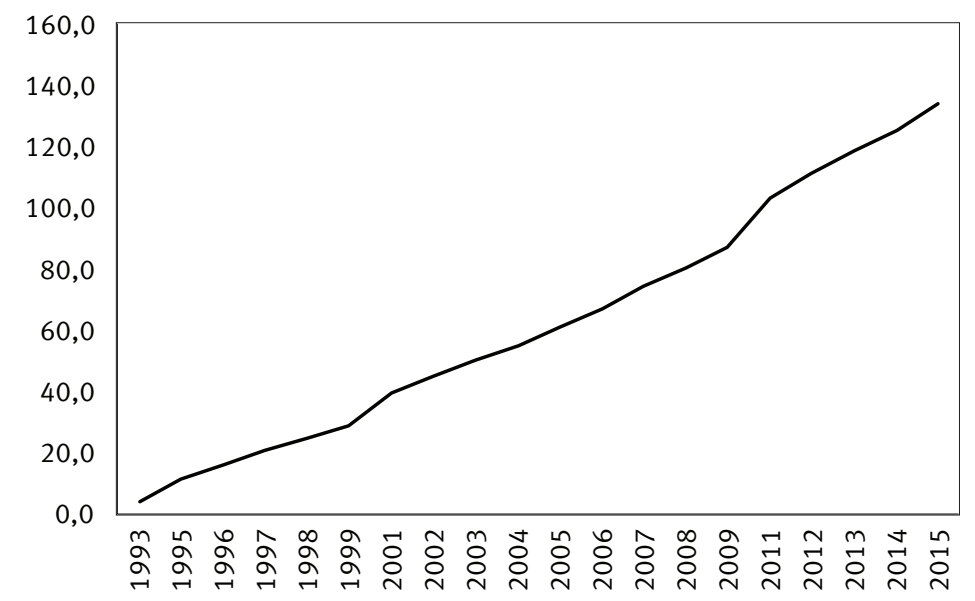

Fonte: IBGE. PNAD. Elaboração dos autores.

Na comparação entre 1992 e 2015, pode ser observada redução da probabilidade de sobrevivência na condição de sem filho em relação à categoria de referência, indicando homogeneização das chances de entrar na maternidade entre as mulheres, pois o diferencial em relação à unidade decresceu em todos os níveis de escolaridade. Ressalta-se, porém, que essa queda foi menor para aquelas com 15 ou mais anos de estudos (de $39,2 \%$ para $36,5 \%$ ), sugerindo fortalecimento da relação entre investimento em capital humano de alta qualificação e adiamento ou mesmo abdicação da maternidade, para essa parcela da população. Tais evidências estão de acordo com o exposto, por exemplo, por Teixeira (1999), Barbosa e Rocha-Coutinho (2007), Rios-Neto e Guimarães (2014), Lima et al. (2017) e Andrade e Cunha (2021), para o Brasil, e Brewster e Rindfuss (2000), Mills et al. (2011) e Blau e Winkler (2017), para economias mais desenvolvidas.

Em relação à cor ou raça, a diferença na probabilidade de sobrevivência sem filhos de brancas e não brancas foi estatisticamente significativa, porém, a magnitude do efeito não é alta. A partir de 1995, o efeito é positivo, indicando que a chance de sobrevivência das mulheres brancas é superior à das não brancas e, no período, em média, esse efeito é de $1,1 \%$, conforme a especificação (5). No entanto, esse coeficiente apresenta queda quando são incluídas as variáveis binárias para captar as coortes de nascimento e os efeitos dos ciclos econômicos, especificação (7).

As mulheres com cônjuge ou casadas em 1992 tinham 15,8\% menos probabilidade de sobreviverem sem filhos do que as solteiras, mas, em 2015, tais chances caíram para apenas 4,4\%. Essa queda sugere arrefecimento da relação entre casamento e maternidade, 
fenômeno semelhante ao apontado por Greenwood, Guner e Vandenbroucke (2017) para os EUA. Por sua vez, em todas as especificações, a posição de chefe de família para a muIher mostrou menor probabilidade de sobreviver sem filho. Todavia, também se observa declínio no impacto dessa condição nas chances de a mulher permanecer sem filho, pois era de menos 25,7\%, em 1992, diminuindo para menos 9,4\%, em 2015.

Quando se trata da condição de ocupação, pode-se notar que as mulheres na PEA têm maior probabilidade de sobreviver sem filho do que as inativas ou que não participam do mercado de trabalho, uma vez que os coeficientes estimados foram positivos e significativos em todas as especificações. No entanto, essa probabilidade, após subir continuamente de 1992 a 2005, atingiu o seu menor valor em 2015. Isso está alinhado com o indicado na seção anterior de atenuação da associação negativa entre maternidade de primeira ordem e participação no mercado de trabalho no período mais recente.

Portanto, há evidências de que a participação no mercado laboral está relacionada à menor taxa de fecundidade feminina observada no Brasil ao longo das últimas duas décadas. Ou seja, ao se dedicar à sua carreira profissional, a mulher pode estar renunciando à maternidade como uma condição relevante para sua inserção social, fenômeno já destacado por Brewster e Rindfuss (2000) e Greenwood, Guner e Vandenbroucke (2017), em países desenvolvidos; para o Brasil essa temática foi abordada por Cunha e Vasconcelos (2016).

A localização também se mostrou um fator relevante, principalmente levando em conta as grandes desigualdades regionais do Brasil. Lembrando que a região Norte é a referência, mulheres residentes no Sudeste, em 1992, tinham a maior probabilidade de não ter filhos, com chances de mais 5,3\%. Já para a região Centro-Oeste, no mesmo ano, esse valor era de menos $0,4 \%$. Vale ressaltar também a evolução da região Nordeste que, em 1992, não apresentava um diferencial significativo e, em 2015, registrava um efeito positivo de $2,7 \%$, ou seja, as chances de as mulheres sobreviverem sem filhos nesta região com o passar dos anos ampliaram-se. Em relação à residência na zona rural ou urbana, a maior parte das especificações foi significativa, indicando que são maiores as chances de sobreviver sem filho nas áreas urbanas. Já o coeficiente da variável região metropolitana também foi positivo e só não significativo no ano de 1995, apontando maior chance de sobrevivência sem filhos em regiões metropolitanas.

Os resultados das estimativas sugerem algumas diferenças na comparação entre 1992 e 2015. Em geral, há uma redução do diferencial estimado em relação às categorias de referência, porém, para as brancas residentes no Sudeste, Nordeste e Sul esse diferencial aumentou. Destaca-se o fato de que em 1992 a variável binária para raça não foi estatisticamente significativa, mas em 2015 essa variável se torna significativa, sugerindo que as desigualdades entre as mulheres brancas e não brancas foram intensificadas no período analisado. Outra característica a ser ressaltada é a dimensão espacial, que aponta a existência de diferenças regionais no fenômeno de adiamento da maternidade, pois, enquanto em 1992 apenas as regiões Sudeste e Sul apresentavam coeficiente positivo e significativo, 
em 2015 o Nordeste, além do Sudeste e Sul, também tem diferencial significativo e positivo. Ademais, o Centro-Oeste mantém diferencial negativo neste último ano.

Por sua vez, na análise do período de 1992 até 2015, é possível traçar um perfil das mulheres com maiores chances de adiar a maternidade no Brasil, pois esse fenômeno atinge de forma diferenciada alguns grupos de mulheres. Verificou-se que as brancas, solteiras, que não são chefes de família, residentes nas áreas urbanas, metropolitanas e no Sudeste do país têm maiores chances de postergar a maternidade. Ademais, notadamente as mais qualificadas e atuantes no mercado de trabalho têm as maiores chances de adiamento do primeiro filho em, respectivamente, 39,1\% e 13,1\%, conforme especificação (5). Portanto, entre os fatores associados ao adiamento estudados, destacam-se os investimentos em capital humano e a inserção no mercado de trabalho. Resultados condizentes com os 20 pontos percentuais superiores na taxa de participação das mulheres brasileiras com mais de 11 anos de estudo ante aquelas com dez ou menos, conforme indicado por Barbosa (2014). Esses resultados estão de acordo com as evidências de Coutinho e Golher (2018) de que, após adquirirem um maior nível de escolaridade, as mulheres desejam mais filhos.

Conforme Scavone (2001), em uma reflexão sociológica sobre as mudanças nos padrões e experiências da maternidade contemporânea, a escolha da maternidade é um fenômeno moderno consolidado no decorrer do século XX, com o avanço da industrialização e da urbanização. 0 rompimento com o determinismo biológico da maternidade, promovido pelo controle parcial da procriação - a contracepção medicalizada e as tecnologias reprodutivas - e o desenvolvimento do conceito de parentalidade vêm construindo novas tendências de relações parentais e de gênero, refletindo as mudanças no interior da família e da sociedade.

Portanto, os resultados desse trabalho sugerem que, cada vez mais, as mulheres brasileiras, principalmente aquelas com maior nível de escolaridade, ao longo dos anos, têm resistido a arcar com o chamado "custo da maternidade", como definido por Gustafsson (2001), Miller (2009) e Buckles (2008), procrastinando o evento de maternidade para idades mais avançadas e buscando também na vida profissional sua satisfação pessoal.

\section{Considerações finais}

Este trabalho teve como objetivo verificar se há evidências e os fatores associados ao fenômeno de adiamento da maternidade no Brasil. Utilizaram-se as informações da PNAD, para os anos de 1992 até 2015, e o método de análise de sobrevivência. Assim, considerando os dois grupos de mulheres expostas ao fenômeno do adiamento - aquelas sem filhos e as com filho com menos de um ano -, foi possível avaliar se as mulheres têm "sobrevivido" mais sem filhos ou adiado sua maternidade.

Verificou-se que, de 1992 para 2015, as mulheres não estão apenas deixando de ter filhos, mas suas chances de sobrevivência sem filhos aumentaram, sendo que esse fenômeno não atinge de forma homogênea todas as mulheres ou regiões do país. Em geral, foi possível observar que esse fenômeno é mais intenso entre as brancas, mais qualificadas, 
solteiras, que não são chefes da família, participantes do mercado de trabalho, residentes em áreas urbanas, metropolitanas e no Sudeste.

Portanto, os resultados do trabalho reforçam as evidências de que, no Brasil, as mulheres estão adiando a primeira gravidez. Isso possivelmente está relacionado às aspirações femininas no mercado de trabalho, em especial para aquelas com os maiores investimentos em capital humano, pois as estimativas apontam mais anos de estudo e a participação no mercado de trabalho como preponderantes na associação ao adiamento da maternidade. Ademais, esse fenômeno do adiamento é crescente, sendo que em 2015 as chances de sobrevivência sem filhos eram 134,4\% maiores do que em 1992.

0 adiamento da maternidade se, por um lado, possibilita às mulheres condições mais favoráveis para tal engajamento e, por conseguinte, reconhecimento no mercado de trabaIho, ajudando, inclusive, a reduzir as desigualdades salariais em relação aos homens, por outro, afeta o padrão e a taxa de natalidade de toda a sociedade. Construir formas para compatibilizar as crescentes aspirações profissionais das mulheres ao exercício da maternidade já se tornou um desafio importante para diversas nações, tais como Japão, Itália e países escandinavos, preocupadas com as repercussões econômicas, previdenciárias e sociais do encolhimento populacional. As evidências aqui discutidas, relacionadas com a rápida e acentuada queda na taxa de fecundidade no Brasil, mostram a urgência de se inserir esse tema na pauta da sociedade e do governo brasileiro.

\section{Referências}

ADSERA, A.; MENENDEZ, A. Fertility changes in Latin America in the context of economic uncertainty. Institute for the Study of Labor (IZA), 2009. (Discussion Papers, n. 4019).

ALDRIGHI, J. D.; WAL, M. L.; SOUZA, S. R. R. K.; CANCELA, F. Z. V. The experiences of pregnant women at an advanced maternal age: an integrative review. Revista da Escola de Enfermagem da USP, v. 50, n. 3, p. 509-518. 2016.

AMUEDO-DORANTES, C.; KIMMEL, J. The motherhood wage gap for women in the United States: the importance of college and fertility delay. Review of Economics of the Household, n. 3, p. 17-48. 2005.

ANDRADE, J. L.; CUNHA, M. S. Impact of postponing motherhood on women's income in Brazil. Revista de Economia Aplicada, v. 25, p. 65-92, 2021.

ARPINO, B.; ESPING-ANDERSEN, GØSTA, E-A, PESSIN, L. How do changes in gender role attitudes towards female employment influence fertility? A macro-level analysis. European Sociological Review, v. 31, n. 3, p. 370-382, 2015.

BAILEY, M. J. More power to the pill: the impact of contraceptive freedom on women's lifecycle labor supply. Quarterly Journal of Economics, v. 121, n. 1, p. 289-320, 2006.

BARBOSA, A. L. N. H. Participação feminina no mercado de trabalho brasileiro. Nota Técnica Mercado de Trabalho, n. 57, Brasília, Ipea. 2014.

BARBOSA, P. Z.; ROCHA-COUTINHO, M. L. Maternidade: novas possibilidades, antigas visões. Psicologia Clínica, v. 19, n. 1, p. 163 -185, 2007. 
BERQUÓ, E. S.; CAVENAGHI, S. M. Notas sobre os diferenciais educacionais e econômicos da fecundidade no Brasil. Revista Brasileira de Estudos de População, v. 13, n. 2, p. 471-482, 2014.

BILLARI, F. C.; LIEFBROER, A. C.; PHILIPOV, D. The postponement of childbearing in Europe: driving forces and implications. Vienna Yearbook of Population Research, v. 4, p. 1-17, 2006.

BLACKBURN, M. L.; BLOOM, D. E.; NEUMARK, D. Fertility timing, wages, and human capital. Journal of Population Economics, v. 6, n. 1, p. 1-30, 1993.

BLAU, F. D.; KAHN, L. M. Changes in the labor supply behavior of married women: 1980-2000. Journal of Labor Economics, v. 25, n. 3, p. 393-438, 2007.

BLAU, F. D.; WINKLER, A. E. Women, work, and family. Massachusetts: National Bureau of Economic Research, 2017. (NBER Working Paper Series, n. 23644).

BONGAARTS, J. The proximate determinants of fertility. Technology in Society, v. 9, n. 3-4, p. 243-260, 1987.

BONGAARTS, J.; FEENEY, G. On quantum and tempo of fertility. Population and Development Review, v. 24, n. 2, p. 271-291, 1998.

BREWSTER, K. L.; RINDFUSS, R. R. Fertility and women's employment in industrialized nations. Annual Review of Sociology, v. 26, p. 271-296, 2000.

BRITO, F. Transição demográfica e desigualdades sociais no Brasil. Revista Brasileira de Estudos da População, v. 25, n. 1, p. 5-26, 2008.

BUCKLES, K. Understanding the returns to delayed childbearing for working women. The American Economic Review, v. 98, n. 2, p. 403-407, 2008.

CASTANHEIRA, H. C.; KOHLER, H-P. It is lower than you think: recent total fertility rates in Brazil and possibly other Latin American countries. The Population Studies Center, 2015. (PSC Working Paper Series, n. 63).

COUTINHO, R. Z.; GOLGHER, A. B. Modelando os determinantes próximos da fecundidade para o Brasil: 0 advento das preferências competitivas. Revista Brasileira de Estudos de População, v. 35, n. 1, p. 1-28, 2018.

CUNHA, M. S.; VASCONCELOS, M. R. Fecundidade e participação no mercado de trabalho brasileiro. Nova Economia, v. 26, n. 1, p. 179-206, 2016.

GOLDIN, C.; KATZ, L. F. The power of the pill: oral contraceptives and women's career and marriage decisions. Journal of Political Economy, v. 110, n. 4, p. 730-70, 2002.

GREENE, W. Econometric analysis. 8. ed. New York: Pearson, 2018.

GREENWOOD, J.; GUNER, N.; VANDENBROUCKE, G. Family economics writ large. Journal of Economic Literature, v. 55, n. 4, p. 1346-1434, 2017.

GUSTAFSSON, S. Optimal age at motherhood. Theoretical and empirical considerations on postponement of maternity in Europe. Journal of Population Economics, v. 14, p. 225-247, 2001.

IBGE. Síntese dos indicadores sociais: uma análise das condições de vida da população brasileira. Rio de Janeiro: Coordenação de População e Indicadores Sociais, 2010.

KAHN, L. B.; LANGE, F. Employer learning, productivity and the earnings distribution: evidence from performance measures. Review of Economic Studies, v. 81, n. 4, p. 1575-1613, 2014.

KNODEL, J.; CHAMRATRITHIRONG, A.; DEBAVALYA, N. Thailand's reproductive revolution: rapid fertility decline in a third-world setting. Madison, Wisconsin: University of Wisconsin Press, 1987. 
LATIMER, N. R. Survival analysis for economic evaluations alongside clinical trials - extrapolation with patient-level data. National Institute for Health and Care Excellence, 2013. (Technical Support Document, n. 14).

LEE, C.; GRAMOTNEV, H. Motherhood plans among young Australian women: who e want's children these days? Journal of Health Psychology, v. 11, n. 1, p. 5-20, 2006.

LEIBENSTEIN, H. The economic theory of fertility decline. Quarterly Journal of Economics, v. 89, n. 1, p. 1-31. 1975.

LERIDON, H. Can assisted reproduction technology compensate for the natural decline in fertility with age? A model assessment. Human Reproduction, v. 19, n. 7, p. 1548-1553, 2004.

LIMA, E. E. C.; ZEMAN, K.; NATHAN, M.; CASTRO, R.; SOBOTKA, T. Twin peaks: the emergence of bimodal fertility profiles in Latin America. Vienna: Vienna Institute of Demography, 2017. (VID Working Paper, 10/2017 and Human Fertility Database Research Report 2017-004).

MCDONALD, P. Societal foundations for explaining low fertility: gender equity. Demographic Research, v. 28, p. 981-994, 2013.

MILLS, M.; MENCARINI, L.; TANTURRI, M. L.; BEGALL, K. Gender equity and fertility intentions in Italy and the Netherlands. Demographic Research, v. 18, p. 1-26, 2008.

MILLS, M.; RINDFUSS, R. R.; MCDONALD, P.; VELDE, E. Why do people postpone parenthood? Reasons and social policy incentives. Human Reproduction Update, v. 17, n. 6, p. 848-860, 2011.

MILLER, A. Motherhood delay and the human capital of the next generation. The American Economic Review, v. 99, n. 2, p.154-158, 2009.

MIRANDA-RIBEIRO, A. Reconstrução de histórias de nascimentos a partir de dados censitários: aspectos teóricos e evidências empíricas. Tese (Doutorado) - Universidade Federal de Minas Gerais, Belo Horizonte, 2007.

MIRANDA-RIBEIRO, A.; GARCIA, R. A. Transition or transitions? Analyzing the fertility decline in Brazil in the light of educational levels. Revista Latinoamericana de Población, v. 7, n. 13, p. 91-106, 2013.

MIRANDA-RIBEIRO, A.; GARCIA, R. A.; FARIA, T. C. A. B. Baixa fecundidade e adiamento do primeiro filho no Brasil. Revista Brasileira de Estudos de População, v. 36, p. 1-18, 2019.

MIRANDA-RIBEIRO, A.; RIOS-NETO, E. L. G.; ORTEGA, J. A. Efeito tempo, quantum e efeito parturição na transição da fecundidade no Brasil: aplicação do modelo de Kohler \& Ortega. In: ENCONTRO NACIONAL DE ESTUDOS POPULACIONAIS, 15, 2006, Caxambu/MG. Anais [...]. Caxambu: Abep, 2006.

MIRANDA-RIBEIRO, A.; RIOS-NETO, E. L. G.; ORTEGA, J. Declínio da fecundidade no Brasil e México e o nível de reposição: efeitos tempo, parturição e quantum. In: WONG, L. (ed.). Poblacion y salud sexual y reproductiva em América Latina. Rio de Janeiro: Alap, 2008. p. 81-100.

MIRANDA-RIBEIRO, A.; RIOS-NETO, E. L. G.; CARVALHO, J. A. M. Efeitos tempo, parturição e quantum no Brasil: indicadores de período e evidências empíricas. Revista Brasileira de Estudos de População, v. 30, n. 1, p. 145-170, 2013.

MYRSKYLÄ, M.; KOHLER, H.-P.; BILLARI, F. C. High development and fertility: fertility at older reproductive ages and gender equality explain the positive link. University of Pennsylvania, 2011. (Population Studies Center Working Paper Series, n. 11-06).

NÍBHROLCHAIN, M.; BEAUJOUAN, E. Fertility postponement is largely due to rising educational enrolment. Population Studies, v. 66, n. 3, p. 311-327, 2012. 
O'DONOGHUE, C.; MEREDITH, D.; O'SHEA, E. Postponing maternity in Ireland. Institute for the Study of Labor (IZA), 2009. (Discussion Papers, n. 4192).

RIOS-NETO, E. L. G.; GUIMARÃES, R. R. M. The educational gradient of low fertility in Latin America. In: ANNUAL MEETING OF POPULATION ASSOCIATION OF AMERICA. Proceedings [...]. Boston, MA: PAA, 2014.

ROSERO-BIXBY, L.; CASTRO-MARTÍN, T.; MARÍN-GARCIA, T. Is Latin America starting to retreat from early and universal childbearing? Demographic Research, v. 20, p. 169-194, 2009.

SCAVONE, L. Maternidade: transformações na família e nas relações de gênero. Interface: Comunicação, Saúde, Educação, v. 5, n. 8, p. 47-60, 2001.

SOBOTKA, T. Postponement of childbearing and low fertility in Europe. University Medical Center Groningen, 2004.

SOUZA, L. R.; RIOS-NETO, E. L. G.; QUEIROZ, B. L. A relação entre parturição e trabalho feminino no Brasil. Revista Brasileira de Estudos de População, v. 28, n. 1, p. 57-79, 2011.

THE WORLD BANK. World Bank Open Data. 2018. Disponível em: https://data.worldbank.org/. Acesso em: 18 fev. 2018.

TEIXEIRA, E. T. N. Adiamento da maternidade: ser mãe depois dos 35 anos. Mestrado (Programa de Pós-Graduação da Fundação Oswaldo Cruz) - Escola Nacional de Saúde Pública, Departamento de Ciências Sociais, Rio de Janeiro, 1999.

ZALDI, B.; MORGAN, S. P. The second demographic transition theory: a review and appraisal. Annual Review of Sociology, v. 43, p. 473-492, 2017.

\section{Sobre os autores}

Marina Silva da Cunha é doutora em Economia Aplicada pela Universidade de São Paulo (USP) e graduada em Ciências Econômicas pela Universidade Estadual de Londrina (UEL). Professora titular do Departamento de Economia e do Programa de Pós-Graduação em Ciências Econômicas da Universidade Estadual de Maringá (UEM) e bolsista produtividade em pesquisa do CNPq.

Ana Maria Paula Rosa é doutoranda em Economia com ênfase em Economia do Desenvolvimento pela Universidade Federal do Rio Grande do Sul (UFRGS), mestre em Teoria Econômica pela Universidade Estadual de Maringá (UEM) e graduada em Ciências Econômicas pela Universidade Federal de Uberlândia (UFU).

Marcos Roberto Vasconcelos é doutor em Ciência Econômica pela Universidade Estadual de Campinas (Unicamp) e graduado em Ciências Econômicas pela Universidade Federal do Paraná (UFPR). Professor associado do Departamento de Economia e do Programa de Pós-Graduação em Ciências Econômicas da Universidade Estadual de Maringá (UEM).

\section{Endereço para correspondência}

Marina Silva da Cunha

Programa de Pós-Graduação em Ciências Econômicas, Universidade Estadual de Maringá Av. Colombo, 5790, bloco C34, sala 5

87020-900 - Maringá-PR, Brasil 


\section{Ana Maria Paula Rosa}

Programa de Pós-Graduação em Ciências Econômicas, Universidade Estadual de Maringá Av. Colombo, 5790, bloco C34, sala 5

87020-900 - Maringá-PR, Brasil

Marcos Roberto Vasconcelos

Programa de Pós-Graduação em Ciências Econômicas, Universidade Estadual de Maringá Av. Colombo, 5790, bloco C34, sala 5

87020-900 - Maringá-PR, Brasil

\section{Abstract}

Evidence and factors associated with the maternity postponement phenomenon in Brazil

This paper aims to contribute to the literature on the phenomenon of postponement of motherhood in Brazil, as well as to analyze its main associated factors. The research analyzes the period from 1992 to 2015, considering information from the National Household Sample Survey and the survival analysis that makes it possible to characterize those women who are surviving without children or postponing their first child. The results show a growing tendency in maternity postponement in Brazil and that those most likely to postpone motherhood are white, single, living in urban, metropolitan areas and in the Southeast region. In addition, it was possible to identify that among the main factors that contribute to this trend is investment in human capital and participation in the labor market, which are preponderant for the postponement of motherhood.

Keywords: Postponement of motherhood. First child. Labor market.

\section{Resumen}

\section{Evidencia y factores asociados al fenómeno de aplazamiento de la maternidad en Brasil}

Este trabajo tiene como objetivo contribuir a la literatura sobre el fenómeno del aplazamiento de la maternidad en Brasil, así como analizar sus principales factores asociados. La investigación analiza el período 1992-2015, considerando la información de la Encuesta Nacional de Muestras de Hogares y el análisis de supervivencia que permite caracterizar a las mujeres que sobreviven sin hijos o posponen a su primer hijo. Los resultados muestran una tendencia creciente de posponer la maternidad en Brasil y que quienes tienen más probabilidades de posponer la maternidad son blancas y solteras, y viven en áreas urbanas, metropolitanas y en el sudeste. Además, fue posible identificar que entre los principales factores que contribuyen a esta tendencia se encuentra la inversión en capital humano y la participación en el mercado laboral, que son preponderantes para el aplazamiento de la maternidad.

Palabras clave: Aplazamiento de la maternidad. Primer hijo. Mercado laboral. 